\title{
Editorial
}

\section{Radiation-induced fracture}

Paul M. Arnold, M.D.

Department of Neurosurgery, University of Kansas Medical Center, Kansas City, Kansas

The advent of any new medical treatment is accompanied by a wave of enthusiasm, followed by the attendant realization that no new therapy is without risks. Such is the case with stereotactic body radiotherapy (also referred to as spine stereotactic radiosurgery [SRS]), which has been increasingly used in the treatment of metastatic spinal tumors. Stereotactic radiosurgery applies a concentrated dose of radiation to the tumor itself and away from the spinal cord, which would permit the possibility of local cure of the neoplasm, with less risk to the spinal cord compared with standard radiation therapy. Several large studies have been published assessing the safety and efficacy of this technique., $4,5,8$

In addition to the potential for bone and spinal cord damage from SRS, there is also the risk of vertebral compression fracture (VCF), estimated to be $11 \%-39 \% .^{1-3,6}$ Patients who received the highest biologically effective dose (20-24 Gy in one setting) were at greatest risk for developing $\mathrm{VCF}^{3}$ and the etiology was hypothesized to be due to radiation-induced effects within the tumor and bone that caused structural weakening of the vertebral body. Open surgery, further radiation therapy, or chemotherapy would then be options for the treatment of this clinical problem.

However, as demonstrated by Al-Omair et al., ${ }^{1}$ radiation necrosis and not tumor progression may be the cause of VCF following SRS. The authors performed a biopsy in 2 patients who demonstrated VCF several years after SRS. Magnetic resonance imaging findings were consistent with tumor progression, but the histopathological findings were consistent with necrosis or fibrosis. Both patients underwent kyphoplasty and were spared further invasive therapy.

These important findings present a dilemma for the physician faced with this clinical problem, and there are currently no management guidelines to direct treatment. As the use of SRS becomes more widespread, there are likely to be more of these patients. Should all patients who have VCF after SRS undergo biopsy? The authors recommend biopsy "when it is unclear based on imaging alone if true progression has occurred," but this is on the basis of a single report describing 2 patients. Magnetic resonance imaging or PET scanning does not always allow these 2 pathological processes, radiation necrosis or tumor progression, to be distinguished, thus leaving the diagnostic decision in the hands of the practicing clinician. If radiation necrosis is diagnosed, what is the optimal treatment?

As this problem becomes more prevalent, it is likely that indications for biopsy will emerge. In the meantime, this paper has spotlighted the discrepancy between radiology and pathology. The practicing spine surgeon will now have to remember that fibrotic or necrotic changes in the bone may mimic tumor progression and perhaps consider recommending biopsy at this diagnostic branch point. The strategy combining biopsy with concurrent kyphoplasty is attractive; however, is this the best treatment? It is obvious that more studies will need to be carried out to determine the extent of the problem and guide therapy, but this manuscript offers the necessary initial data in this (currently) little-known clinical dilemma.

(http://thejns.org/doi/abs/10.3171/2013.1.SPINE121161)

\section{Disclosure}

Dr. Arnold is a consultant for Medtronic, Inc. He reports no financial or material support for this editorial.

\section{References}

1. Al-Omair A, Smith R, Kiehl TR, Lao L, Yu E, Massicotte EM, et al: Radiation-induced vertebral compression fracture following spine stereotactic radiosurgery: clinicopathological correlation. Report of 2 cases. J Neurosurg Spine [epub ahead of print March 15, 2013. DOI: 10.3171/2013.2.SPINE12739]

2. Boehling NS, Grosshans DR, Allen PK, McAleer MF, Burton AW, Azeem S, et al: Vertebral compression fracture risk after stereotactic body radiotherapy for spinal metastases. Clinical article. J Neurosurg Spine 16:379-386, 2012

3. Cunha MV, Al-Omair A, Atenafu EG, Masucci GL, Letourneau D, Korol R, et al: Vertebral compression fracture (VCF) after spine stereotactic body radiation therapy (SBRT): analysis of predictive factors. Int J Radiat Oncol Biol Phys 84: e343-e349, 2012

4. Hyde D, Lochray F, Korol R, Davidson M, Wong CS, Ma L, et al: Spine stereotactic body radiotherapy utilizing cone-beam CT image-guidance with a robotic couch: intrafraction motion analysis accounting for all six degrees of freedom. Int $\mathbf{J}$ Radiat Oncol Biol Phys 82:e555-e562, 2012

5. Masucci GL, Yu E, Ma L, Chang EL, Letourneau D, Lo S, et al: Stereotactic body radiotherapy is an effective treatment 


\section{Editorial}

in reirradiating spinal metastases: current status and practical considerations for safe practice. Expert Rev Anticancer Ther 11:1923-1933, 2011

6. Rose PS, Laufer I, Boland PJ, Hanover A, Bilsky MH, Yamada $\mathrm{J}$, et al: Risk of fracture after single fraction image-guided intensity-modulated radiation therapy to spinal metastases. J Clin Oncol 27:5075-5079, 2009

7. Sahgal A, Larson DA, Chang EL: Stereotactic body radiosurgery for spinal metastases: a critical review. Int J Radiat Oncol Biol Phys 71:652-665, 2008 (Erratum in J Radiat Oncol Biol Phys 74:323, 2009)

8. Sahgal A, Ma L, Gibbs I, Gerszten PC, Ryu S, Soltys S, et al: Spinal cord tolerance for stereotactic body radiotherapy. Int J Radiat Oncol Biol Phys 77:548-553, 2010

\section{Response}

ArJun Sahgal, M.D.

\begin{abstract}
Department of Radiation Oncology, Sunnybrook Health Sciences Centre and Princess Margaret Hospital, University of Toronto, Ontario, Canada
\end{abstract}

We appreciate the clear comments by Dr. Arnold as he describes that indeed no treatment is without risks and that with spine SRS, also known as spine stereotactic body radiotherapy, the complication of VCF is not to be considered lightly. This complication is emerging with high crude risks ranging from $11 \%$ to $39 \% .^{1,2,4}$ The dilemma lies in the SRS-induced VCF as to whether the cause is disease progression or simply loss of the mechanical integrity of the vertebral segment with the tumor still locally controlled. Our report describes for the first time the potential for osteoradionecrosis in the differential diagnosis of SRS-induced VCF. This has major implications as patients may be at risk of undergoing unnecessary salvage open surgery; subjected to additional radiation therapy, which increases the risk of radiationinduced myelopathy; or may have to undergo a change in their systemic therapy, which is not insignificant given the relatively few lines of therapy to which most patients with advanced cancer have access.

In several clinical and radiological situations it may indeed be clear that progression has occurred post-SRS, and the most common pattern of failure is new or progressive epidural disease. ${ }^{5}$ However, when dealing with a clinical and radiological situation where the follow-up MR image shows isolated changes within the vertebral bone and $\mathrm{VCF}$, it is imperative that spine surgeons and oncologists keep osteoradionecrosis in mind as a potential diagnosis rather than assume tumor progression, in particular when the patient's overall disease status is stable and the patient is on a regimen of active systemic therapy. In these situations, biopsy should be considered.

We agree that the optimal therapy for SRS-induced $\mathrm{VCF}$ is unknown; however, some form of reconstructive surgery may be required to palliate the pain and stabilize the patient. These clinical situations are also why multidisciplinary teams and tumor boards are encouraged for spine SRS practice, as the communication between medical and radiation oncologists, spine surgeons, and radiologists is essential in guiding appropriate decision making, in particular, when in the early stages of a new therapy. ${ }^{6}$ Without a doubt in North America we are now in the era of spine SRS, as it is increasingly being practiced in both community and academic clinics, ${ }^{3}$ and, as we have learned from years of experience with brain SRS, radionecrosis will become a diagnostic dilemma in these patients. We cannot emphasize enough the role of imaging research in these patients to provide a noninvasive means to discriminate between tumor progression and osteoradionecrosis; however, we have again learned from more than 20 years of brain SRS experience, specifically research in the area of brain radionecrosis, that when in doubt biopsy remains the gold standard.

\section{References}

1. Boehling NS, Grosshans DR, Allen PK, McAleer MF, Burton AW, Azeem S, et al: Vertebral compression fracture risk after stereotactic body radiotherapy for spinal metastases. Clinical article. J Neurosurg Spine 16:379-386, 2012

2. Cunha MV, Al-Omair A, Atenafu EG, Masucci GL, Letourneau D, Korol R, et al: Vertebral compression fracture (VCF) after spine stereotactic body radiation therapy (SBRT): analysis of predictive factors. Int J Radiat Oncol Biol Phys 84: e343-e349, 2012

3. Pan H, Simpson DR, Mell LK, Mundt AJ, Lawson JD: A survey of stereotactic body radiotherapy use in the United States. Cancer 117:4566-4572, 2011

4. Rose PS, Laufer I, Boland PJ, Hanover A, Bilsky MH, Yamada $\mathrm{J}$, et al: Risk of fracture after single fraction image-guided intensity-modulated radiation therapy to spinal metastases. J Clin Oncol 27:5075-5079, 2009

5. Sahgal A, Bilsky M, Chang EL, Ma L, Yamada Y, Rhines LD, et al: Stereotactic body radiotherapy for spinal metastases: current status, with a focus on its application in the postoperative patient. A review. J Neurosurg Spine 14:151-166, 2011

6. Sahgal A, Roberge D, Schellenberg D, Purdie TG, Swaminath A, Pantarotto J, et al: The Canadian Association of Radiation Oncology scope of practice guidelines for lung, liver and spine stereotactic body radiotherapy. Clin Oncol (R Coll Radiol) 24:629-639, 2012

Please include this information when citing this paper: published online March 15, 2013; DOI: 10.3171/2013.1.SPINE121161. 